\title{
Global pattern of leaf litter nitrogen and phosphorus in woody plants
}

\author{
Hongzhang KANG ${ }^{1}$, Zaijun XIN ${ }^{1,2}$, Björn BERG ${ }^{3,4}$, Paul J. Burgess ${ }^{5}$, Qunlu LIU ${ }^{1}$, Zhicheng LIU ${ }^{1}$, \\ Zhaohua LI ${ }^{2}$, Chunjiang LIU ${ }^{1,6 *}$ \\ ${ }^{1}$ School of Agriculture and Biology, Shanghai Jiao Tong University, Dongchuan Rd. 800, Shanghai 200240, P.R. China \\ ${ }^{2}$ College of Resources and Environmental Sciences, Hubei University, Wuhan 430062, P.R. China \\ ${ }^{3}$ Dipartimento Biologia Strutturale e Funzionale. Complesso Universitario, Monte S. Angelo, Via Cinthia, IT-80126 Napoli, Italy \\ ${ }^{4}$ Department of Forest Ecology, University of Helsinki, Latokartanonkaari 7, 00014, Finland \\ ${ }^{5}$ School of Applied Sciences, Cranfield University, Cranfield, Bedfordshire, MK43 0AL, UK \\ ${ }^{6}$ Key Laboratory of Urban Agriculture (South), Ministry of Agriculture, People's Republic of China, Dongchuan Rd. 800, \\ Shanghai 200240, P.R. China
}

(Received 14 July 2009; accepted 17 March 2010)

\begin{abstract}
Keywords:
nitrogen /

phosphorus /

woody plants /

leaf-litter /

climate
\end{abstract}

\begin{abstract}
- Forest ecosystems exert an important influence on global biogeochemical cycles. A global dataset of nitrogen $(\mathrm{N})$ and phosphorus $(\mathrm{P})$ concentrations in leaf-litter of woody plants was compiled from the literature. Among the 677 data sets, 482 included P concentrations and the N:P ratio.

- At a global scale, the mean leaf-litter $\mathrm{N}$ and $\mathrm{P}$ and $\mathrm{N}: \mathrm{P}$ ratio were $10.9 \mathrm{mg} \mathrm{g}^{-1}, 0.85 \mathrm{mg} \mathrm{g}^{-1}$ and 18.3 , respectively. Leaf-litter $\mathrm{N}$ and $\mathrm{P}$ were significantly correlated. When the data was grouped by continents, the highest mean $\mathrm{N}$ was found in Africa $\left(19.5 \mathrm{mg} \mathrm{g}^{-1}\right.$ ), and the lowest in North America (8.18 $\mathrm{mg} \mathrm{g}^{-1}$ ). $\mathrm{P}$ was significantly smaller in the Asian Islands (Japan and Malaysia, $0.44 \mathrm{mg} \mathrm{g}^{-1}$ ) than on the Asian mainland. For the global dataset, leaf-litter $\mathrm{N}$ increased linearly with mean annual temperature and annual precipitation and decreased with latitude. Although leaf-litter P showed no significant relationship with temperature, it declined linearly with precipitation and there was a convex quadratic relationship with latitude. For the global dataset and also for different functional groups (e.g. shrubs, evergreen broadleaf, deciduous broadleaf, and conifers) the leaf-litter N:P ratio generally followed a positive linear relationship with temperature and precipitation, and showed a concave quadratic response with latitude.

- The differences in leaf-litter N:P ratio among functional groups and among continents should be taken into account when modeling biogeochemical cycles in different regions as well as on a global scale.
\end{abstract}

\section{INTRODUCTION}

The abscission and decomposition of senesced leaves are important processes in the functioning of ecosystems. The concentrations of nitrogen $(\mathrm{N})$ and phosphorus $(\mathrm{P})$ and their ratios in leaf-litter can determine the litter decay rate, the rate of return to the soil, their subsequent availability for other plants and soil organisms, and potential $\mathrm{N}$ leaching or nitrous oxide release (Berg and McClaugherty, 2003). Forests and woodlands account for about $28 \%$ of the terrestrial surface of the Earth, and hence the abscission and decomposition of the leaves from woody plants form a vital part of the global process of nutrient cycling (Hättenschwiler et al., 2008; McGroddy et al., 2004).

\footnotetext{
* Corresponding author: chjliu@ sjtu.edu.cn
}

The concentration of nutrients in leaf-litter and how this varies globally with climatic factors is an area of active research (Ågren, 2008; Hättenschwiler et al., 2008; Manzoni et al., 2008; McGroddy et al., 2004; Yuan and Chen, 2009b). Aerts (1997) reported that both leaf-litter $\mathrm{N}$ and $\mathrm{P}$ concentrations follow a positive but non-linear relationship with actual evapotranspiration based on a dataset concerning cool and warm temperate sites, the Mediterranean and the humid lowland tropics. Liu et al. (2006) reported that leaf-litter N concentration increased linearly with mean annual temperature (MAT, ${ }^{\circ} \mathrm{C}$ ) and mean annual precipitation (MAP, mm) at a regional scale. Yuan and Chen (2009b) reported a linear increase for the $\mathrm{N}$ concentration and decrease for the $\mathrm{P}$ concentration in leaf-litter with increased MAT and MAP. In addition, for live leaves at a global scale, there is a non-linear relationship between the $\mathrm{N}$ (or P) concentration and climate factors (Reich 
and Oleksyn, 2004; Yin, 1993). The nutrient status of leaflitter nutrient status is primarily the product of the nutrient status of live leaves and the ratio of nutrient resorption back into the plant during senescence (Killingbeck, 1996; Kobe et al., 2005; Ratnam et al., 2008). As an inference, in this context, leaf-litter N (or P) concentration would display a non-linear relationship with climatic factors. Hence the aim of this research is to investigate the relationships based on a new dataset.

One possible reason for different responses with MAT and MAP is the confounding of climatic effects with species effects. Different functional groups such as broadleaf trees, conifers and shrubs can show different concentrations of leaflitter $\mathrm{N}$ and $\mathrm{P}$, with for example conifers generally showing lower values than that for broadleaf trees (Yuan and Chen, 2009b). Differences between leaf-litter chemical traits have also been reported for different biomes (boreal, temperate, and tropical biomes) (McGroddy et al., 2004; Yuan and Chen, 2009b), but not compared between different continents. Coninental differences may also be possible because of differences in geology. For example Han et al. (2005) reported that the low $\mathrm{P}$ concentration of $\mathrm{P}$ in the unsenesced leaves in China was caused by the low availability of $\mathrm{P}$ in Chinese soils.

During recent years, we have compiled a global dataset of leaf-litter $\mathrm{N}$ and $\mathrm{P}$ of woody plants based on a survey of the literature and the Eurasian dataset of Liu et al. (2006). Although this dataset shares 44 papers with Yuan and Chen's (2009b) meta-analysis of global trends of leaf-litter $\mathrm{N}$ and $\mathrm{P}$ reported, this amounts to only $13 \%$ of their dataset. Hence our present dataset is complementary to previous studies and we expect it to improve our understanding of the variations in leaf-litter $\mathrm{N}$ and $\mathrm{P}$ at a global scale.

For a global analysis of leaf-litter $\mathrm{N}$ and $\mathrm{P}$, the role of temperature and precipitation are particularly important. Both can affect the functional type of vegetation and the rate of chemical processes (Liu et al., 2006; Yuan and Chen, 2009b). Other climatic factors that have been implicated include actual evapotranspiration (AET, mm) which when integrated with precipitation it can describe the water balance (Aerts, 1997). Lastly the use of latitude (LAT, defined as degrees away from the Equator) can act as an alternative measure of temperature and water availability combined with seasonality (Berg et al., 1995).

The objectives of this study were to determine at a global scale the leaf-litter N,P and N:P ratio of (1) different functional plant groups, (2) different continental groupings., and (3) the relationship with mean annual temperature, mean annual preciptation and latitude. To achieve these objectives we compiled a global data set of $\mathrm{N}$ and $\mathrm{P}$ concentrations and $\mathrm{N}: \mathrm{P}$ ratios for the leaf-litter of woody plants, by expanding a data set of 204 samples for Eurasia (Liu et al., 2006) to a total of 677 samples worldwide.

\section{METHODS}

\subsection{Data collection}

The data used in this study was compiled from publications on leaf-litter $\mathrm{N}$ and $\mathrm{P}$ concentrations at a global scale (data in Appendix S1, available on line only at www.afs-journal. org). A total of 677 data samples were included, encompassing 401 species from 24 countries. The sites ranged from $41.37^{\circ} \mathrm{S}$ to $68.37^{\circ} \mathrm{N}$ in latitude, from $155.67^{\circ} \mathrm{W}$ to 0 to $151.45^{\circ} \mathrm{E}$ in longitude, from 0 to $2920 \mathrm{~m}$ in altitude, from -4.9 to $30.2{ }^{\circ} \mathrm{C}$ in MAT, and from 200 to $5260 \mathrm{~mm}$ in MAP. The distribution of data was showed in Figure 1.

The studies concerning $\mathrm{N}$-fixing species and the fertilized stands were not included in the dataset in present study. To ensure data comparability, the unit percentage (\%) used by some authors for nutrient concentration was converted to units of $\mathrm{mg} \mathrm{g}^{-1}$. If climate data were not provided in the original data source, MAT and MAP were calculated based on the coordinates and altitudes using the Local Climate Estimator "New_LocClim V1.10" (FAO 2006).

\subsection{Data processing}

The leaf-litter data were analyzed in four functional groups: "shrubs", "coniferous trees", "deciduous broadleaf trees" and "evergreen broadleaf trees" in order to determine differences in $\mathrm{N}$ and $\mathrm{P}$ concentrations and the $\mathrm{N}$ :P ratio. The leaf-litter data were also analysed according to six continental areas: North America (NA), South America (SA), Europe (EU), Africa $(\mathrm{AF})$, and Asian mainland (AM). In view of possible climatic differences due to proximity to the sea, results from Japan and Malaysia were grouped into a separate group called Asian Islands (AI). The means of each group were compared using $t$-tests.

Linear and polynomial regression analyses were also undertaken to establish the best fitting descriptions of $\mathrm{N}$ and $\mathrm{P}$ concentration and N:P ratio in relation to climate (MAT, MAP) and latitude (LAT). The best fitting relationships were determined as those with the highest correlation coefficient $(r)$ and lowest $p$ value. The statistical analyses were performed using Excel (Microsoft Corporation, USA) and SPSS (SPSS Inc., USA).

\section{RESULTS}

\subsection{Leaf-litter $N$ and $P$ concentrations and the $N: P$ ratio}

The mean $\mathrm{N}$ and $\mathrm{P}$ concentrations and $\mathrm{N}: \mathrm{P}$ ratio of woody plant leaf-litter were $10.93 \mathrm{mg} \mathrm{g}^{-1}(n=677, S D=$ $\left.6.48 \mathrm{mg} \mathrm{g}^{-1}\right), 0.85 \mathrm{mg} \mathrm{g}^{-1}\left(n=482, S D=0.71 \mathrm{mg} \mathrm{g}^{-1}\right)$ and $18.32(n=482, S D=11.17)$ respectively (Tab. I). The leaf-litter $\mathrm{N}$ concentration was significantly $(p<0.001)$ and positively correlated with that of $\mathrm{P}\left(r^{2}=0.31\right)$ (Fig. 2).

Leaf-litter $\mathrm{N}$ and $\mathrm{P}$ concentrations were significantly different between shrubs and conifers $(p<0.05)$ (Tab. I). The deciduous and evergreen broadleaf trees had similar values for leaf-litter $\mathrm{N}$ concentration (12.12-12.30 $\mathrm{mg} \mathrm{g}^{-1}$ ) and $\mathrm{P}$ concentration $\left(0.84-0.94 \mathrm{mg} \mathrm{g}^{-1}\right)$. However the $\mathrm{N}: \mathrm{P}$ ratio in evergreen species $(20.7)$ was significantly higher $(p<0.05)$ than that in deciduous broadleaf species (18.2). Compared to the 


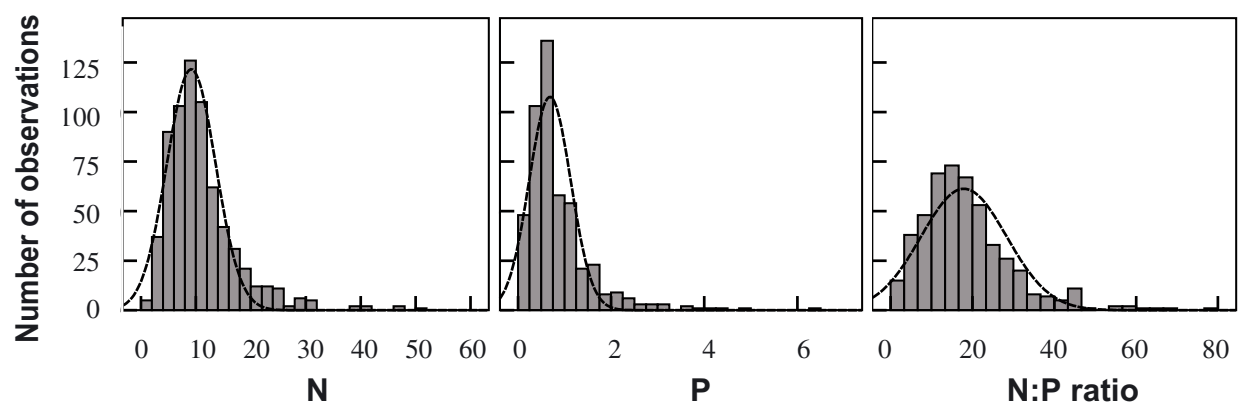

Figure 1. The distribution of leaf-litter $\mathrm{N}$ concentration, $\mathrm{P}$ concentration and $\mathrm{N}: \mathrm{P}$ ratio for woody plants at a global scale (data in Appendix $\mathrm{S} 1)$. The dashed curves in the figures indicate fitted log-normal curves.

Table I. Statistics of leaf-litter N and P concentrations as well as N:P ratio for different functional groups at a global scale (the data used is listed as Appendix S1). Standard deviation (SD) is given.

\begin{tabular}{|c|c|c|c|c|c|}
\hline Stoichiometric traits & $n$ & Mean & Min. & Max. & SD \\
\hline \multicolumn{6}{|l|}{ Woody plants (all samples) } \\
\hline $\mathrm{N}\left(\mathrm{mg} \mathrm{g}^{-1}\right)$ & 677 & 10.93 & 0.60 & 50.50 & 6.48 \\
\hline $\mathrm{P}\left(\mathrm{mg} \mathrm{g}^{-1}\right)$ & 482 & 0.85 & 0.10 & 6.40 & 0.71 \\
\hline $\mathrm{N}: \mathrm{P}$ ratio & 482 & 18.32 & 0.20 & 79.00 & 11.17 \\
\hline \multicolumn{6}{|l|}{ Shrubs } \\
\hline $\mathrm{N}\left(\mathrm{mg} \mathrm{g}^{-1}\right)$ & 61 & $10.24 \mathrm{a}^{*}$ & 3.80 & 38.10 & 6.06 \\
\hline $\mathrm{P}\left(\mathrm{mg} \mathrm{g}^{-1}\right)$ & 42 & $0.92 \mathrm{a}$ & 0.10 & 3.07 & 0.74 \\
\hline $\mathrm{N}: \mathrm{P}$ ratio & 42 & $15.98 \mathrm{ac}$ & 2.63 & 46.00 & 11.32 \\
\hline \multicolumn{6}{|l|}{ Evergreen broadleaf } \\
\hline $\mathrm{N}\left(\mathrm{mg} \mathrm{g}^{-1}\right)$ & 176 & $12.30 \mathrm{~b}$ & 1.41 & 30.60 & 6.02 \\
\hline$P\left(\mathrm{mg} \mathrm{g}^{-1}\right)$ & 141 & $0.84 \mathrm{a}$ & 0.10 & 6.40 & 0.86 \\
\hline $\mathrm{N}: \mathrm{P}$ ratio & 141 & $20.67 b$ & 0.80 & 69.33 & 11.68 \\
\hline \multicolumn{6}{|l|}{ Deciduous broadleaf } \\
\hline $\mathrm{N}\left(\mathrm{mg} \mathrm{g}^{-1}\right)$ & 306 & $12.12 b$ & 0.76 & 50.50 & 6.69 \\
\hline $\mathrm{P}\left(\mathrm{mg} \mathrm{g}^{-1}\right)$ & 234 & $0.90 \mathrm{a}$ & 0.10 & 4.40 & 0.65 \\
\hline $\mathrm{N}: \mathrm{P}$ ratio & 234 & $18.20 \mathrm{a}$ & 0.20 & 79.00 & 11.46 \\
\hline \multicolumn{6}{|l|}{ Conifers } \\
\hline $\mathrm{N}\left(\mathrm{mg} \mathrm{g}^{-1}\right)$ & 134 & $6.69 \mathrm{c}$ & 0.60 & 38.10 & 4.71 \\
\hline $\mathrm{P}\left(\mathrm{mg} \mathrm{g}^{-1}\right)$ & 65 & $0.62 b$ & 0.10 & 2.42 & 0.47 \\
\hline $\mathrm{N}: \mathrm{P}$ ratio & 65 & $15.13 c$ & 2.33 & 38.00 & 7.31 \\
\hline
\end{tabular}

* Different letters indicate significant differences among different functional groups $(t$-test, $p<0.05)$.

two groups of broadleaf trees, coniferous litter had significantly $(p<0.05)$ lower concentrations of $\mathrm{N}\left(6.69 \mathrm{mg} \mathrm{g}^{-1}\right)$ and $\mathrm{P}\left(0.62 \mathrm{mg} \mathrm{g}^{-1}\right)$ and a lower N:P ratio (15.13) (Tab. I).

For the different continental regions, the mean level of leaflitter nitrogen for the samples from Africa $\left(19.15 \mathrm{mg} \mathrm{g}^{-1}\right)$ was greater $(p<0.001)$ than in each of the other five regions (Fig. 3A). The lowest $\mathrm{N}$ concentration $\left(8.18 \mathrm{mg} \mathrm{g}^{-1}\right)$ which was obtained for North America was lower $(p<0.05)$ than in each of the five other regions (Tab. II). The lowest leaf-litter $\mathrm{P}$ concentration $\left(0.44 \mathrm{mg} \mathrm{g}^{-1}\right)$ was obtained for the "Asian Island" grouping (Fig. 3B). This value was significantly lower $(p<0.01)$ than that in any other region with the exception of North America (Fig. 3B, Tab. II). The low value of P for the "Asian Island" grouping resulted in this region also having a
Table II. $t$-test for significant differences in $\mathrm{N}$ and $\mathrm{P}$ concentrations as well as N:P ratio between leaf-litter from different continents (also see Fig. 2).

\begin{tabular}{lccccc}
\hline & SA & EU & AF & AM & AI \\
\hline & Leaf-litter N & & & & \\
NA* $^{*}$ & $<0.001$ & 0.012 & $<0.001$ & $<0.001$ & 0.045 \\
SA & & 0.412 & $<0.001$ & 0.427 & 0.133 \\
EU & & & $<0.001$ & 0.035 & 0.649 \\
AF & & & $<0.001$ & $<0.001$ \\
AM & & & & 0.035 \\
& Leaf-litter P & & & & \\
NA & 0.979 & 0.951 & 0.977 & 0.905 & 0.700 \\
SA & & 0.989 & 0.716 & 0.825 & 0.001 \\
EU & & & 0.671 & 0.697 & 0.004 \\
AF & & & & 0.482 & 0.003 \\
AM & & & & & 0.003 \\
& Leaf-litter N:P ratio & & & & \\
NA & 0.235 & 0.024 & $<0.001$ & 0.007 & $<0.001$ \\
SA & & 0.868 & 0.087 & 0.791 & 0.005 \\
EU & & & $<0.001$ & 0.38 & $<0.001$ \\
AF & & & & 0.025 & 0.072 \\
AM & & & & & $<0.001$ \\
\hline
\end{tabular}

* North America (NA), South America (SA), Europe (EU), Africa (AF), Asian mainland (AM), Asian Islands (AI).

higher $\mathrm{N}: \mathrm{P}$ ratio than each other region with the exception of Africa (Fig. 3C, Tab. II).

\subsection{Variation in leaf-litter $\mathbf{N}$ and $\mathbf{P}$ concentrations and $\mathrm{N}: \mathrm{P}$ ratio with latitude, $\mathrm{MAT}$ and MAP}

For the global dataset, leaf-litter $\mathrm{N}$ concentration increased $(p<0.001)$ linearly with MAT and MAP and decreased $(p<0.001)$ linearly with latitude. By contrast, the leaf-litter $\mathbf{P}$ concentration showed no significant relationship $(p=0.192)$ with MAT, and a negative linear relationship $(p<0.01)$ with MAP. The leaf-litter P concentration also showed a convex quadratic relationship $(p<0.05)$ with LAT, i.e. the lowest values occurred at high or low latitudes. The resulting N:P ratio was positively linear with MAT and MAP $(p<0.001)$ 


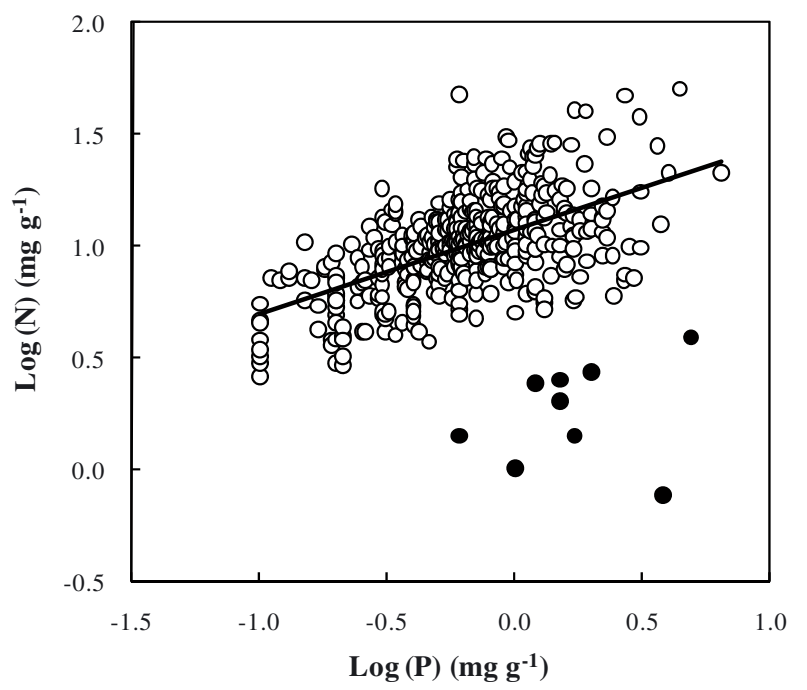

Figure 2. The relationship between leaf-litter $\mathrm{N}$ and $\mathrm{P}$ concentrations in woody plants. Fitted line in the figure follows the model, $\log (\mathrm{N})=$ $0.3772 \log (\mathrm{P})+1.0749\left(r^{2}=0.3141, n=482, p<0.001\right)$. The data indicated with filled circles is not included in the regression.

(Figs. 4 and 5) and showed a concave quadratic relationship $(p<0.001)$ with LAT (Fig. 6, Appendix S3 available on line only at www.afs-journal.org).

Within the relatively small $(n=42-61)$ shrub leaf-litter dataset, the $\mathrm{N}$ concentration showed no significant relationship ( $p>0.24)$ with MAT, MAP or LAT. However, the P concentration did show a significant decrease $(p<0.05)$ with MAT (Fig. 4E). The P concentration also showed $(p<0.01)$ a concave quadratic relationship with MAP (Fig. 5E), and increased $(p<0.05)$ linearly with LAT (Fig. 6E) (regression models are listed in Appendix S3 available online only at www.afs-journal.org). For the shrub dataset, the N:P ratio varied $(p<0.01)$ as a concave quadratic relationship with MAT (Fig. 4C), a positive $(p<0.01)$ linear relationship with MAP (Fig. 5C), and as a concave quadratic relationship with LAT $(p<0.01)$ (Fig. 6C).

Each of the three tree datasets generally showed similar relationships as the global dataset. For each tree dataset leaflitter $\mathrm{N}$ concentration increased $(p<0.001)$ linearly with MAT and decreased $(p<0.01)$ linearly with LAT. Whereas the leaf $\mathrm{N}$ concentration increased $(p<0.01)$ with MAP for the evergreen broadleaf tree and conifer tree groups, the effect was not significant ( $p=0.88$ ) for the deciduous broadleaf tree group. For each of the three datasets the relationships between leaf-litter P concentration and MAT, MAP and LAT were generally not significant $(p>0.05)$. The main exception was that the $\mathrm{P}$ concentration within the deciduous broadleaf tree group varied $(p<0.05)$ in a concave relationship with MAT (Fig. 4K), showed a negative $(p<0.001)$ linear relationship with MAP (Fig. 5K), and had $(p=0.05)$ a convex relationship with LAT (Fig. 6K). The P concentration within the conifer tree group also showed a convex relationship with LAT (Fig. 6O). Lastly in each tree group there were generally significant relationships between N:P ratio and MAT, MAP

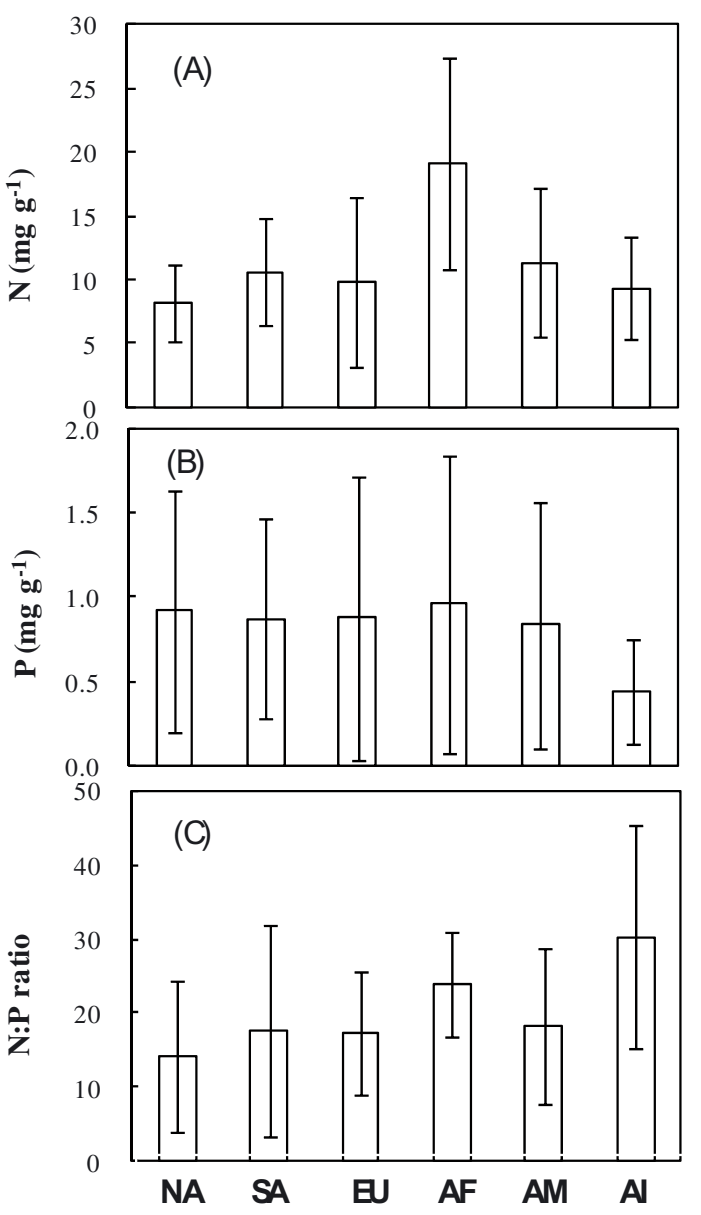

Figure 3. Leaf-litter $\mathrm{N}$ concentration (A), P concentration (B) and $\mathrm{N}$ :P ratio (C) for flora in North America (NA) $(n=116$ for nitrogen and 97 for phosphorus and N:P ratio), South America (SA) $(n=50$ for nitrogen, 19 for phosphorus and N:P ratio), Europe (EU) $(n=189$ for nitrogen, 113 for phosphorus and N:P ratio), Africa (AF) $(n=21$ for nitrogen, phosphorus and $\mathrm{N}: \mathrm{P}$ ratio), Asian mainland (AM) $(n=$ 127 for nitrogen, 103 for phosphorus and N:P ratio) and Asian Islands (AI) $(n=45$ for nitrogen, 33 for phosphorus and $\mathrm{N}: \mathrm{P}$ ratio). Vertical bars indicate standard deviation. Significant differences between the continents and islands are seen in Table II.

and LAT. In each group the N:P ratio increased with MAT, but the effect was only significant $(p<0.05)$ for the "Deciduous broadleaf tree" and "Conifer tree" group (Figs. 4I, 4L and 4O). The N:P ratio increased $(p<0.05)$ linearly with MAP for each group (Figs. 5I, 5L and 5O) and varied $(p<0.01)$ in a concave relationship with LAT (Figs. 6I, 6L and 6O) (Appendix S3).

\section{DISCUSSION}

\subsection{General levels of $N, P$ and $N: P$ ratio in leaf-litter of woody plants}

A number of studies have attempted to establish relationships between climate factors and $\mathrm{N}$ and $\mathrm{P}$ concentration for 


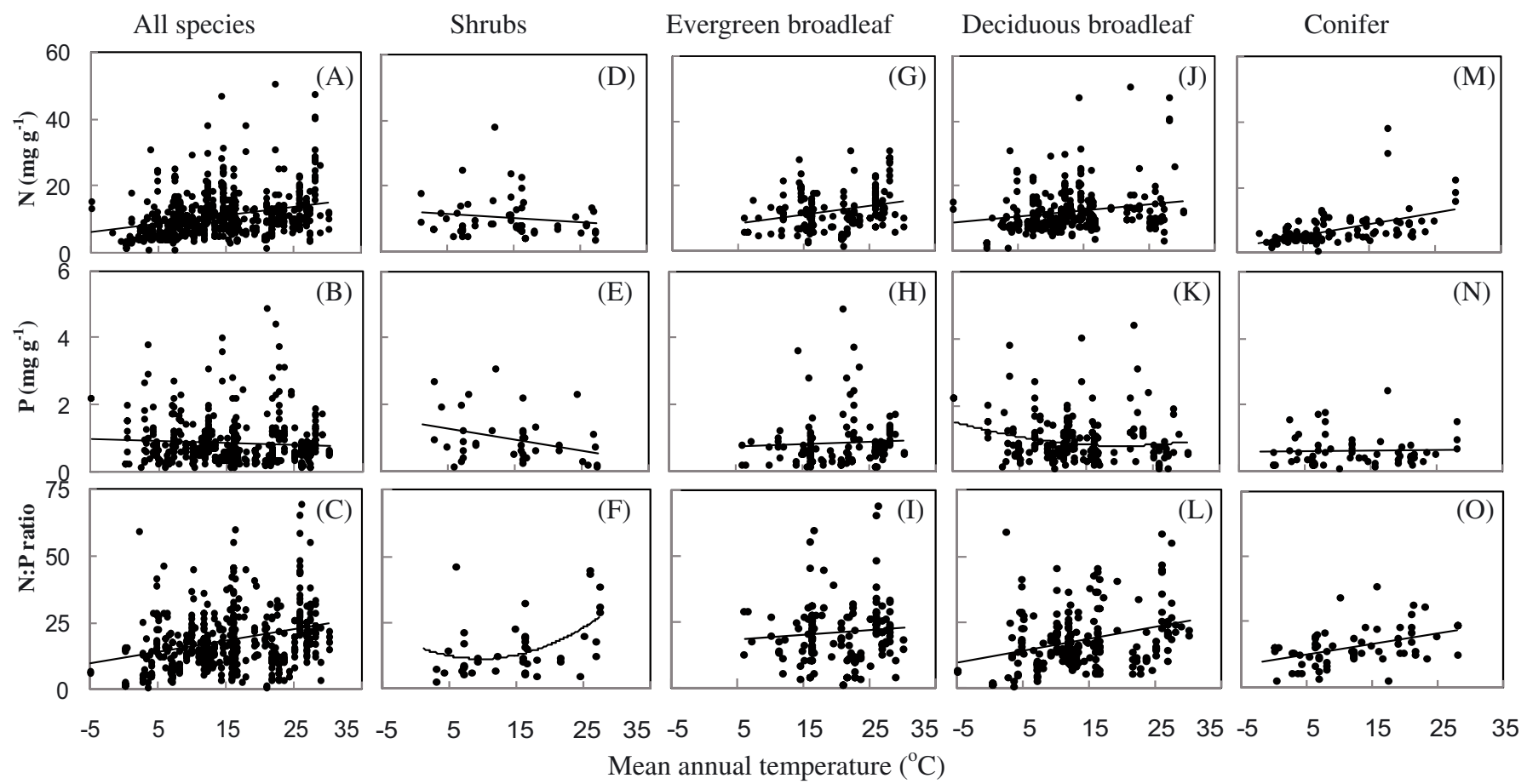

Figure 4. Variation in leaf-litter $\mathrm{N}$ and $\mathrm{P}$ concentrations as well as in $\mathrm{N}: \mathrm{P}$ ratio with mean annual temperature (MAT) for all data combined (A, B, C), shrubs (D, E, F), evergreen broadleaf trees ( G, H, I), deciduous broadleaf trees (J, K, L) and coniferous trees (M, N, O) (corresponding regression equations are given in Tab. S3-1 in Appendix S3).

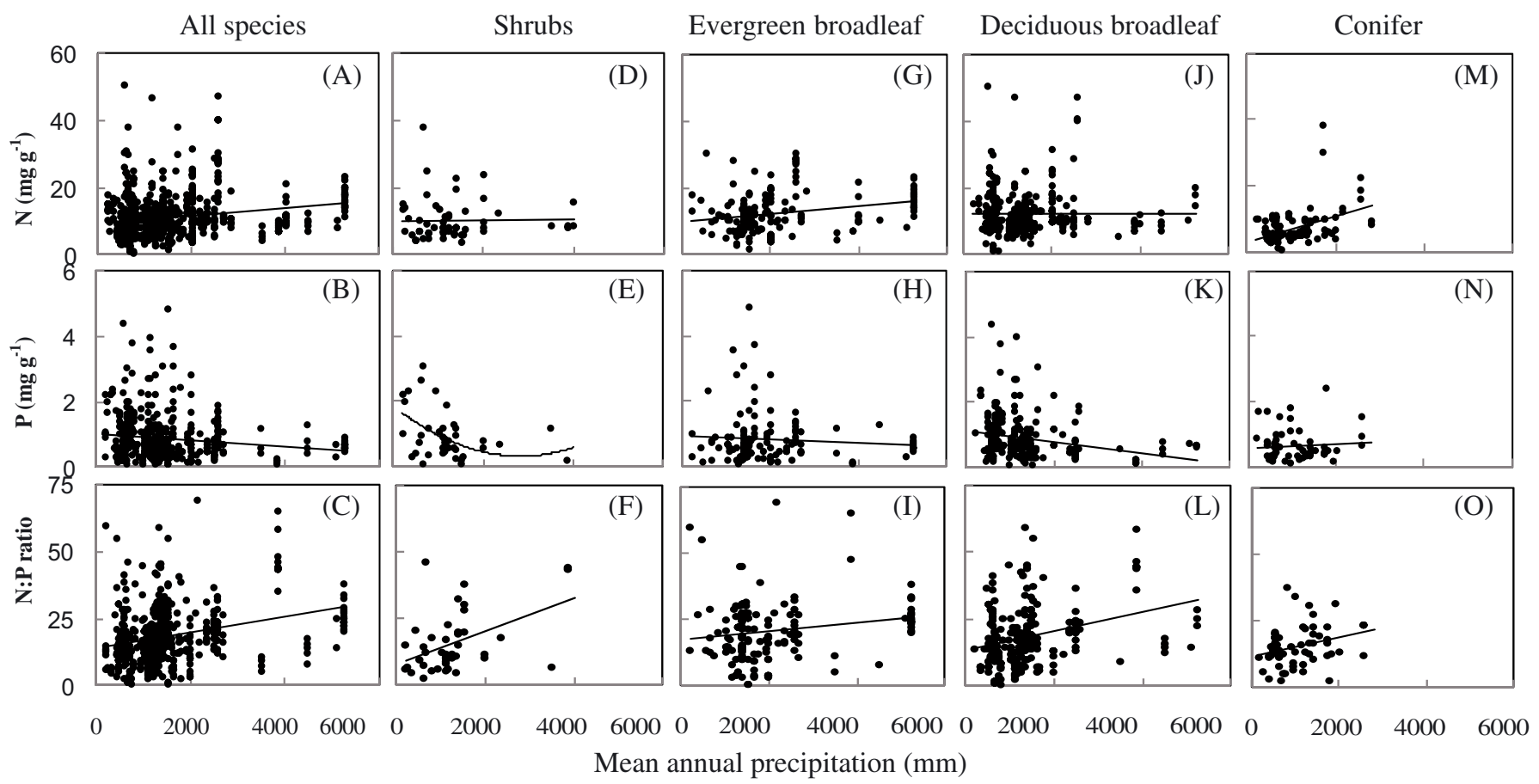

Figure 5. Variation in leaf-litter $\mathrm{N}$ and $\mathrm{P}$ concentrations as well as $\mathrm{N}: \mathrm{P}$ ratio with mean annual precipitation (MAP) for all woody plants combined (A, B, C), shrubs (D, E, F), evergreen broadleaf trees (G, H, I), deciduous broadleaf trees (J, K, L) and coniferous trees (M, N, O) (corresponding regression equations are given in Tab. S3-2 in Appendix S3). 


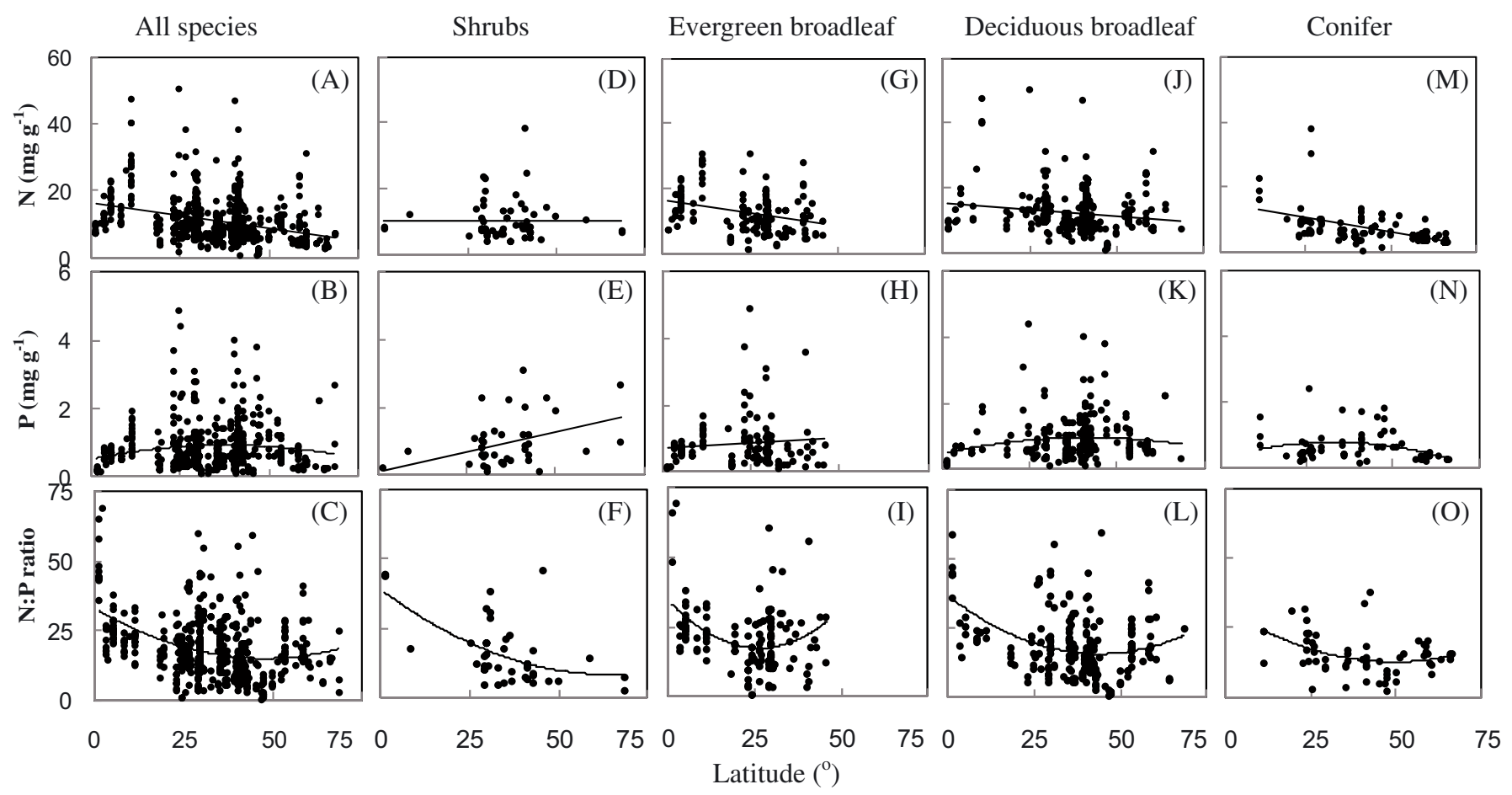

Figure 6. Variation in leaf-litter $\mathrm{N}$ and $\mathrm{P}$ concentrations as well as $\mathrm{N}: \mathrm{P}$ ratio with latitude for all data combined (A, B, C), shrubs (D, E, F), evergreen broadleaf trees $(\mathrm{G}, \mathrm{H}, \mathrm{I})$, deciduous broadleaf trees $(\mathrm{J}, \mathrm{K}, \mathrm{L})$, and coniferous trees $(\mathrm{M}, \mathrm{N}, \mathrm{O})$ (corresponding regression equations are given in Tab. S3-3 in Appendix S3).

the leaf-litter of woody plants at a regional (Aerts, 1997; Liu et al., 2006) and global scale (Aerts, 1997; McGroddy et al., 2004; Yuan and Chen, 2009b). Our study use a new dataset to establish the general patterns in $\mathrm{N}$ and $\mathrm{P}$ concentrations and $\mathrm{N}: \mathrm{P}$ ratios in leaf-litter of woody plants at a global level, showing some inconsistent results with previous studies. The mean nitrogen concentrations reported here for evergreen and deciduous broadleaf trees $\left(12.1-12.3 \mathrm{mg} \mathrm{g}^{-1}\right)$ are higher than values of $9.6-10.3 \mathrm{mg} \mathrm{g}^{-1}$ reported by Yuan and Chen, (2009b). By contrast the mean $\mathrm{N}$ concentration reported here for conifer trees $\left(6.69 \mathrm{mg} \mathrm{g}^{-1}\right)$ is lower than that $\left(7.9 \mathrm{mg} \mathrm{g}^{-1}\right)$ reported by Yuan and Chen (2009b) (Tab. III). The P concentration for deciduous broadleaves $\left(0.9 \mathrm{mg} \mathrm{g}^{-1}\right)$ and conifers $\left(0.6 \mathrm{mg} \mathrm{g}^{-1}\right)$ are similar in the two studies, although the value reported here for evergreen broadleaves $\left(0.84 \mathrm{mg} \mathrm{g}^{-1}\right)$ is higher than that $\left(0.5 \mathrm{mg} \mathrm{g}^{-1}\right)$ reported by Yuan and Chen (2009b).

According to Yuan and Chen (2009b), the N:P ratios of the leaf-litter increased as one moves from boreal to temperate, and then to Mediterranean and tropical forests (Tab. III). Within this study, the N:P ratio also increased as the MAT increased (Fig. 4C) and the highest ratios were found in the "Asian Island" and "Africa" continental regions.

In the present study, mean leaf-litter $\mathrm{N}$ and $\mathrm{P}$ concentrations for all woody plants combined were $10.93 \mathrm{mg} \mathrm{g}^{-1}$ and $0.85 \mathrm{mg}$ $\mathrm{g}^{-1}$, respectively (Tab. I). These averages are $40 \%$ lower than $\mathrm{N}\left(18.3 \mathrm{mg} \mathrm{g}^{-1}\right)$ and $\mathrm{P}\left(1.42 \mathrm{mg} \mathrm{g}^{-1}\right)$ concentrations reported in a global study of live leaves (Reich and Oleksyn, 2004). The lower leaf-litter $\mathrm{N}$ and $\mathrm{P}$ concentrations result from resorption by the plants during leaf senescence. For example Yuan and Chen (2009a) reported resorption efficiencies of about $47 \%$ for nitrogen and 54\% for phosphorus. Aerts (1996) reports a resorption efficiency of about $50 \%$ loss for both $\mathrm{N}$ and $\mathrm{P}$.

\subsection{Global patterns of variation in leaf-litter $\mathbf{N}$ and $\mathbf{P}$ concentrations}

Liu et al. (2006) found that across Europe and Asia, tree leaf-litter $\mathrm{N}$ concentration increased linearly with increasing MAT and MAP $\left(r^{2}=0.45, p<0.001, n=204\right)$. Yuan and Chen (2009b) also found that at a global scale leaf-litter N increased linearly with temperature and precipitation. Our results on leaf-litter N (Figs. 4 and 5) support these two observations. In addition, because mean temperature tends to decrease with increasing latitude, the above relationships means that the leaf-litter $\mathrm{N}$ concentration tends to decrease with latitude at a global scale (Fig. 6). Hence we can conclude that linear models are generally adequate for describing global variations in leaf-litter $\mathrm{N}$ concentration. However at smaller scales, whilst the positive response should still be evident, other relationships have been observed. For instance, Aerts (1997) reported that leaf-litter $\mathrm{N}$ concentration followed a positive nonlinear relationship with actual evapotranspiration (AET) with the data collected from temperate, Mediterranean and tropical 
Table III. Comparisons of leaf-litter concentrations of $\mathrm{N}$ and $\mathrm{P}$ as well as N:P ratio (on a mass basis) in this study with previous ones.

\begin{tabular}{|c|c|c|c|}
\hline & $\mathrm{N}\left(\mathrm{mg} \mathrm{g}^{-1}\right)$ & $\mathrm{P}\left(\mathrm{mg} \mathrm{g}^{-1}\right)$ & $\mathrm{N}: \mathrm{P}$ ratio \\
\hline \multicolumn{4}{|l|}{ This study* } \\
\hline Woody plants & $10.93 \pm 6.48(677)$ & $0.85 \pm 0.71(482)$ & $18.32 \pm 11.17(482)$ \\
\hline Shrubs & $10.24 \pm 6.06(61)$ & $0.92 \pm 0.74(42)$ & $15.96 \pm 11.32(42)$ \\
\hline Evergreen broadleaf & $12.30 \pm 6.02(176)$ & $0.84 \pm 0.86(141)$ & $20.67 \pm 11.68(141)$ \\
\hline Deciduous broadleaf & $12.12 \pm 6.69(306)$ & $0.90 \pm 0.65(234)$ & $18.20 \pm 11.46(234)$ \\
\hline Conifers & $6.69 \pm 4.71(134)$ & $0.62 \pm 0.47(65)$ & $15.13 \pm 7.31(65)$ \\
\hline \multicolumn{4}{|l|}{ Yuan and Chen $(2009 b) \dagger$} \\
\hline Evergreen & 9.6 & 0.5 & \\
\hline Deciduous & 10.3 & 0.9 & \\
\hline Conifers & 7.9 & 0.6 & \\
\hline \multicolumn{4}{|l|}{ Yuan and Chen $(2009 b) \neq$} \\
\hline Tundra & $6.8 \pm 0.3(41)$ & $0.5 \pm 0.1(9)$ & $23.1 \pm 8.9(5)$ \\
\hline Boreal forest & $8.6 \pm 0.3(253)$ & $0.8 \pm 0.0(152)$ & $15.0 \pm 0.9(141)$ \\
\hline Temperate forest & $9.8 \pm 0.2(439)$ & $0.7 \pm 0.0(233)$ & $17.6 \pm 0.6(204)$ \\
\hline Mediterranean forest & $9.6 \pm 0.5(32)$ & $0.6 \pm 0.0(35)$ & $17.8 \pm 1.2(28)$ \\
\hline Tropical forest & $12.5 \pm 0.3(255)$ & $0.4 \pm 0.0(172)$ & $27.3 \pm 1.2(112)$ \\
\hline Grassland & $8.7 \pm 0.5(69)$ & $1.1 \pm 0.1924)$ & $14.7 \pm 8.9(10)$ \\
\hline Average & $10.0 \pm 0.1(1089)$ & $0.7 \pm 0.00(625)$ & $19.2 \pm 0.5(500)$ \\
\hline \multicolumn{4}{|l|}{ McGroddy et al. (2004)II } \\
\hline Woody plants & & & $20.6(99)$ \\
\hline Temperate broadleaf & & & $13.2(30)$ \\
\hline Temperate conifers & & & $11.8(20)$ \\
\hline Tropical broadleaf & & & $28.4(50)$ \\
\hline
\end{tabular}

$*$ Mean $\pm 1 \mathrm{sd}(n) . \dagger$ No sample number was found. $\ddagger$ Mean \pm 1 se $(n)$. If The N:P ratio is calculated from the values on a molar basis.

regions, but with mimimal samples from boreal regions. Berg et al. (1995) established exponential functions $(p<0.001)$ between both $\mathrm{N}$ and $\mathrm{P}$ concentration and MAT and MAP for Scots pine foliar litter across a small transect of MAT from -1.7 to $10.5{ }^{\circ} \mathrm{C}$ and MAP from 443 to $1067 \mathrm{~mm}$. Based on Berg's et al. (1995) data, Oleksyn et al. (2003) showed that for Scots pine, leaf-litter $\mathrm{N}$ decreased with latitude across European continent.

Across the global dataset, leaf-litter P concentration showed no significant relationship with MAT at a global scale, although a negative linear relationship was observed with shrubs and a concave quadratic relationship for deciduous broadleaf trees (Fig. 4, Appendix S3). These results are not consistent with those of Yuan and Chen (2009b) who showed that senesced-leaf $\mathrm{P}$ was negatively and significantly correlated with MAT. Reich and Oleksyn (2004) also showed that P concentrations of non-senesced leaves tended to decline with MAT. The low P concentrations at high temperatures has been related to the high abundance of low-P soils in the tropics due to low P weathering inputs (Chadwick et al., 1999; Walker and Syers, 1976), hydrologic losses of dissolved organic P (Hedin et al., 2003), and sorption of P to soil surfaces (Crews et al., 1995; Walker and Syers, 1976). The resulting low level of soil $P$ results in vegetation with lower P concentrations (Han et al., 2005; Reich, 2005; Reich and Oleksyn, 2004), and higher P resorption by senescing leaves (Yuan and Chen, 2009a). By contrast at high latitudes within a European study, Oleksyn et al. (2003) demonstrated that the P concentration of unscenesced Scots pine needles remained relatively consistent at latitudes between 47 and $55^{\circ} \mathrm{N}$ but there was a significant decline between 63 and $65^{\circ} \mathrm{N}$. However because the relative level of $\mathrm{P}$ resorption by the tree increased steadily with latitude, the $\mathrm{P}$ concentration of the leaf-litter also declined steadily between 47 and $65^{\circ} \mathrm{N}$. In addition to these within-species effects, as one moves from low to high latitudes, the abundance of leaflitter from evergreen broadleaf trees (which generally has a high $\mathrm{P}$ concentration) decreases and the abundance of conifer trees (which tend to have a low $\mathrm{P}$ concentration) increases. Hence within the global dataset the principal pattern of $\mathrm{P}$ concentration with latitude is of low values in the tropics and at high latitudes with higher values at mid-latitudes (Figs. 6B, $6 \mathrm{~K}, 6 \mathrm{~N})$.

\subsection{Global patterns of variation in leaf-litter $\mathrm{N}: P$ ratio}

Our results show that litter-leaf N:P ratio generally increased linearly with MAT and MAP (Figs. 4 and 5). This is consistent with the observations of Yuan and Chen (2009b), and can largely be attributed to the increases in leaf-litter $\mathrm{N}$ concentration with MAT and MAP being greater than any associated decline in $\mathrm{P}$ concentration. An increase in the N:P ratio of unsenesced leaves with increased temperature has also been observed by Reich and Oleksyn (2004) and Han et al. (2005).

In terms of latitude, the highest $\mathrm{N}: \mathrm{P}$ ratios tended to be at low latitudes with the lowest values at mid-latitudes, with some evidence that N:P ratios start to increase slightly towards 
the highest latitudes. Again these results arise from the combination of the general decline in $\mathrm{N}$ concentration with latitude being superimposed on a generally convex relationship between $\mathrm{P}$ concentration and latitude. As explained earlier leaflitter $\mathrm{P}$ concentrations tend to be reduced near the equator due to low levels of soil $\mathrm{P}$, and at high latitudes by low mineralization rates and relatively high rates of $\mathrm{P}$ resorption. Within this study this latitude effect only became apparent by the use of a non-linear model (Fig. 6, Appendix S3).

\section{CONCLUSION}

Based on a global dataset different from previous ones, our results support previous observations that leaf-litter $\mathrm{N}$ shows a positive linear relationship with both MAT and MAP at a global scale. Although there was no significant relationship between $\mathrm{P}$ concentration and MAT, our analysis supports previous observations that leaf-litter $P$ can decline with MAP. The net result of these is that the $\mathrm{N}: \mathrm{P}$ ratio tends to increase with MAT and MAP. A key result is that the leaf-litter P concentration tended to show a convex relationship with latitude with the highest values occurring at latitudes of between 25 and $50^{\circ}$. Hence because the $\mathrm{N}$ concentration tends to decline with latitude, the greatest N:P ratios tend to occur at low latitudes, with the lowest values at mid-latitudes before increasing slightly at the highest latitudes. In addition, evident differences in leaflitter $\mathrm{N}$ and $\mathrm{P}$ concentrations exist among some continents or between the mainland and island in Asia area. These results are of clear importance in modeling biogeochemical cycling and particularly the probable responses of litter chemistry to global climate change.

Acknowledgements: The first two authors, H.Z. Kang and Z.J. Xin, contributed equally to this work. We are grateful to Dr. Rongzhou Man for his comments and suggestions for improving this paper. Our thanks go to two anonymous reviewers for their inspiring comments and constructive suggestions for improving this paper. This work was financially supported by National Natural Science Foundation of China (NSFC, Nos. 30671674 and 30800138), Science and Technology Commission of Shanghai Municipality (STCSM, No. 072307063).

\section{REFERENCES}

Aerts R., 1996. Nutrient resorption from senescing leaves of perennials: Are there general patterns? J. Ecol. 84: 597-608.

Aerts R., 1997. Climate, leaf litter chemistry and leaf litter decomposition in terrestrial ecosystems: A triangular relationship. Oikos 79: 439_ 449.

Ågren G.I., 2008. Stoichiometry and nutrition of plant growth in natural communities. Annu. Rev. Ecol. S. 39: 153-170.

Berg B., Calvo de Anta R., Escudero A., Johansson M.B., Laskowski R., Madeira M., McClaugherty C., Meentemeyer V., Reurslag A., and Virzo De Santo A., 1995. The chemical composition of newly shed needle litter of different pine species and Scots pine in a climatic transect. Long-term decomposition in a Scots pine forest X. Can. J. Bot. 73: 1423-1435.

Berg B. and McClaugherty C., 2003. Plant litter: Decomposition, humus formation. Carbon sequestration. Springer-Verlag, Berlin.

Chadwick O.A., Derry L.A., Vitousek P.M., Huebert B.J., and Hedin L.O., 1999. Changing sources of nutrients during four million years of ecosystem development. Nature 397: 491-497.

Crews T.E., Kitayama K., Fownes J.H., Riley R.H., Herbert D.A., Mueller-Dombois D., and Vitousek P.M., 1995. Changes in soil phosphorus fractions and ecosystem dynamics across a long chronosequence in Hawaii. Ecology 76: 1407-1424.

Han W., Fang J., Guo D., and Zhang Y., 2005. Leaf nitrogen and phosphorus stoichiometry across 753 terrestrial plant species in China. New Phytol. 168: 377-385.

Hättenschwiler S., Aeschlimann B., Coûteaux M.M., Roy J., and Bonal D., 2008. High variation in foliage and leaf litter chemistry among 45 tree species of a neotropical rainforest community. New Phytol. 179: $165-75$.

Hedin L.O., Vitousek P.M., and Matson P.A., 2003. Nutrient losses over four million years of tropical forest development. Ecology 84: 22312255.

Killingbeck K.T., 1996. Nutrients in senesced leaves: Keys to the search for potential resorption and resorption proficiency. Ecology 77: $1716-1727$.

Kobe R.K., Lepczyk C.A., and Iyer M., 2005. Resorption efficiency decreases with increasing green leaf nutrients in a global data set. Ecology 86: 2780-2792.

Liu C., Berg B., Kutsch W., Westman C.J., Ilvesniemi H., Shen X., Shen G., and Chen X., 2006. Leaf litter nitrogen concentration as related to climatic factors in eurasian forests. Global Ecol. Biogeogr. 15: 438444.

Manzoni S., Jackson R.B., Trofymow J.A., and Porporato A., 2008. The global stoichiometry of litter nitrogen mineralization. Science 321: 684.

McGroddy M.E., Daufresne T., and Hedin L.O., 2004. Scaling of C: $\mathrm{N}: \mathrm{P}$ stoichiometry in forests worldwide: Implications of terrestrial redfield-type ratios. Ecology 85: 2390-2401.

Oleksyn J., Reich P.B., Zytkowiak R., Karolewski P., and Tjoelker M.G., 2003. Nutrient conservation increases with latitude of origin in european pinus sylvestris populations. Oecologia 136: 220-235.

Ratnam J., Sankaran M., Hanan N.P., Grant R.C., and Zambatis N., 2008. Nutrient resorption patterns of plant functional groups in a tropical savanna: Variation and functional significance. Oecologia 157: 141151.

Reich P.B., 2005. Global biogeography of plant chemistry: Filling in the blanks. New Phytol. 168: 263-266.

Reich P.B. and Oleksyn J., 2004. Global patterns of plant leaf N and P in relation to temperature and latitude. Proc. Natl. Acad. Sci. USA 101: 11001-11006.

Walker T.W. and Syers J.K., 1976. The fate of phosphorus during pedogenesis. Geoderma 15: 1-19.

Yin X., 1993. Variation in foliar nitrogen concentration by forest type and climate gradients in North America. Can. J. For. Res. 23: 1578-1602.

Yuan Z.Y. and Chen H.Y.H., 2009a. Global-scale patterns of nutrient resorption associated with latitude, temperature and precipitation. Global Ecol. Biogeogr.18: 11-18.

Yuan Z.Y. and Chen H.Y.H., 2009b. Global trends in senesced-leaf nitrogen and phosphorus. Global Ecol. Biogeogr. 18: 532-542. 